\title{
Evaluation of Asterion Morphometry in Terms of
}

\section{Clinical Anatomy}

\author{
Sinem Akkaşoğlu ${ }^{1^{\star}}$, Mine Farimaz ${ }^{2}$, Hilal Akdemir Aktaş ${ }^{3}$, Hakan Ocak ${ }^{4}$, Ömür Dilek Erdal ${ }^{5}$, Mustafa \\ Fevzi Sargon ${ }^{6}$, Selma Çalişkan ${ }^{1}$
}

${ }^{1}$ Department of Anatomy, Faculty of Medicine, Ankara Yuldrrm Beyazut University, Ankara, Turkey

${ }^{2}$ Department of Anatomy, Faculty of Medicine, Ufuk University, Ankara, Turkey

${ }^{3}$ Department of Anatomy, Faculty of Medicine, Hacettepe University, Ankara, Turkey

${ }^{4}$ Department of Anatomy, Faculty of Medicine, Karadeniz Technical University, Ankara, Turkey

${ }^{5}$ Department of Anthropology, Faculty of Letters, Hacettepe University, Ankara, Turkey

${ }^{6}$ Department of Anatomy, Faculty of Medicine, Attlim University, Ankara, Turkey

\begin{abstract}
Asterion is the junction of lambdoid, parietomastoid and occipitomastoid sutures and it corresponds to the location of the posterolateral fontanelle. It is close related to the location of junction of transverse and sigmoid sinuses.

Mastoid process, posterior end of zygomatic arch, external occipital protuberance and lambda are bony features in close proximity of asterion. In the present study we measured the distance between asterion and each of aforementioned bony points.

Twenty human dry skulls were included in this study. Distance between asterion and mastoid process was $43.65 \pm 6.75 \mathrm{~mm}$ on the left side and $45.01 \pm 6.04 \mathrm{~mm}$ on the right side. Distance between asterion and posterior end of zygomatic arch was $43.97 \pm 7.37 \mathrm{~mm}$ on the left side and $43.95 \pm 7.02 \mathrm{~mm}$ on the right side. Distance between asterion and external occipital protuberance was $62.59 \pm$ $8.83 \mathrm{~mm}$ on the left side and $54.75 \pm 5.57 \mathrm{~mm}$ on the right side. Distance between asterion and lambda was $81.40 \pm 7.36 \mathrm{~mm}$ on the left side and $82 \pm 4.96 \mathrm{~mm}$ on the right side.

In $84 \%$ of the cases asterion was at the junction of transverse and sigmoid sinuses. In $12 \%$ of the cases asterion was below the junction of transverse and sigmoid sinuses. In $4 \%$ of the cases asterion was above the junction of transverse and sigmoid sinuses. Asterion is the essential point to indicate safety zone for surgical approach and to determine sex and age. It is of great interest of anatomists, anthropologists, forensic experts, radiologists and neurosurgeons
\end{abstract}

Key Words: Asterion, skull, neurosurgery

\section{Introduction}

Asterion is the junction of lambdoid, parietomastoid and occipitomastoid sutures and it corresponds to the location of the posterolateral fontanelle which closes at the end of the first year of the life $(1,2,3)$. It is close related to the location of junction of transverse and sigmoid sinuses (2).

Asterion is a surgical landmark for lateral approach to posterior cranial fossa $(1,4,5)$. Vascular, inflammatory, neoplastic, or traumatic lesions in the posterior cranial fossa are common issues which require surgery (1). Surgeons dealing with deep anatomical structures must have detailed anatomical knowledge about superficial projections of these deep structures. Asterion provides a reliable surface point to indicate underlying structures.

Initial burr hole placed before craniotomy is essential to prevent large craniotomy and sinus injury. It is also necessary for shorter surgery time $(1,4,5)$. Initial burr hole and following craniotomy are necessary for correct orientation of posterolateral cranial surgery. Asterion which is a surface landmark for the underlying sinuses can be localized by the aid of palpable bony features. Mastoid process, posterior end of zygomatic arch, external occipital protuberance and lambda are bony features in close proximity of asterion. In the present study we measured the distance between asterion and each of aforementioned bony points.

Wormian bones are small ossicles which vary in shape, size and number. They are found along fontanelles and sutures (6). Asterion morphology is classified in two types in terms of presence of Wormian bones. Wormian bones are visible at the asterion in Type 1 while no Wormian bones are found in Type 2 (7). Type 1 asterion variations cause diagnostic pitfalls in X-rays and lead complications during craniotomy. In the present study all samples had Type 2 asterion morphology. 
Asterion is also used in sex and age determination. Its' importance as a craniometric point was evaluated in many previous studies $(8,9,10)$.

\section{Materials and Methods}

Twenty human dry skulls were included in this study. 20 skulls with known age (18-50 years) and gender (11 males and 9 females) were evaluated. None of the skulls had bony malformations and sign of trauma scar. Morphometric characteristics of 40 asterion were evaluated on either side of 20 skulls.

Sex determination in the human skeletal remains has based on diagnostic morphological differences between the two biological sexes. In this study, supra orbital ridge, supra orbital margin, orbital form, zygomatic arc, frontal eminence, mastoid process, inferior nuchal line, mental eminence and masseteric tuberosity on the mandible were morphologically assessed for form and shape to determine sex. Age at death determination of these skulls was based on patterns of cranial obliteration.

A digital caliper was used for measurements. To minimize inter observer errors single researcher carried out measurements. Measurements were taken from apex of mastoid process to asterion, from posterior end of zygomatic arch to asterion, from external occipital protuberance to asterion and from lambda to asterion (Fig 1 and Fig 2). Relation of asterion to junction of sigmoid sinus and transverse sinus was also evaluated.

Results were analyzed by SPSS 21 for Windows XP version, mean and standard deviation were recorded.

\section{Results}

Mean and standard deviation of all measurements were reported on right and left sides.

Distance between asterion and mastoid process was $43.65 \pm 6.75 \mathrm{~mm}$ on the left side and $45.01 \pm 6.04 \mathrm{~mm}$ on the right side. Distance between asterion and posterior end of zygomatic arch was $43.97 \pm 7.37 \mathrm{~mm}$ on the left side and 43.95 $\pm .02 \mathrm{~mm}$ on the right side. Distance between asterion and external occipital protuberance was $62.59 \pm 8.83 \mathrm{~mm}$ on the left side and $54.75 \pm 5.57 \mathrm{~mm}$ on the right side. Distance between asterion and lambda was $81.40 \pm 7.36 \mathrm{~mm}$ on the left side and $82 \pm 4.96 \mathrm{~mm}$ on the right side.

In $84 \%$ of the cases asterion was at the junction of transverse and sigmoid sinuses. In $12 \%$ of the cases asterion was below the junction of transverse and sigmoid sinuses. In $4 \%$ of the cases asterion was above the junction of transverse and sigmoid sinuses.

\section{Discussion}

Asterion is the articulation site of occipital, parietal and temporal bones. It is a common center of interest for anatomists, neurosurgeons, radiologists, anthropologists and forensic experts.

Madodin et al studied sex determination on mastoid triangle. Mastoid triangle is an area on the side of the skull bounded by imaginary lines interconnecting three craniometric points: porion, asterion and mastoid. It is used by forensic experts and is dimorphic among males and females. Asterion forms the posterior superior angle of this sexually dimorphic triangle (8). Blessing et al also studied sex determination using mastoid triangle on Nigerian population. Their result indicating mastoid triangle as a sexually dimorphic parameter was in consistent with the result of Madodin et al (10). Orish et al developed another triangle for sex determination called IAO (Inion-opistocranium-asterion) triangle. IOA triangle is located on the posterolateral aspect of the skull. They concluded that IAO triangle showed high level of sexual dimorphism (9). Determination of sex from skull is of great interest for scientists. There for various craniometric points and measurements were studied by researches along history. Asterion is common point for different anthropometric techniques. In the present study sex determination of the samples were made. Of the 20 skulls in our study 11 were male and 9 were female.

Because asterion is a surgical landmark for transverse sinus surgery, its variations were studied many times by researches. Asterion is one of the sites including Wormian bones which vary in shape, size and number $(6,11,12,13)$. Neurosurgeons should be careful when forming burr hole during posterolateral surgical approach to cranium because of the high incidence of Wormian bones in asterion (6). In the present study there was no Wormian bone in our samples. Sudha et al classified asterion morphology in two types in terms of presence of Wormian bones. Wormian bones are visible at the asterion in Type 1 while no Wormian bones are found in Type 2. They indicated Type 1 asterion incidence $8.6 \%$ on the right side, $6.6 \%$ on the left side and $1.6 \%$ bilaterally (7). Havaldar et al compared types of asterion between gender cathegories. Type 1 was $18.25 \%$ in males, $20.59 \%$ in females and $19.2 \%$ in total, Type II was $81.75 \%$ in males, $79.41 \%$ in females and $80.8 \%$ in total (14). Singh reported Type 1 prevalence 16.36\% in the study performed on Indian dry skulls (15). Basnet et al reported Type 1 prevalence $74.4 \%$ in their study including 176 hemicraniums (16). Wormian bones at asterion may resemble fracture in X-rays. Radiologists should keep Type 1 asterion in

East J Med Volume:24, Number:4, October-December/2019 


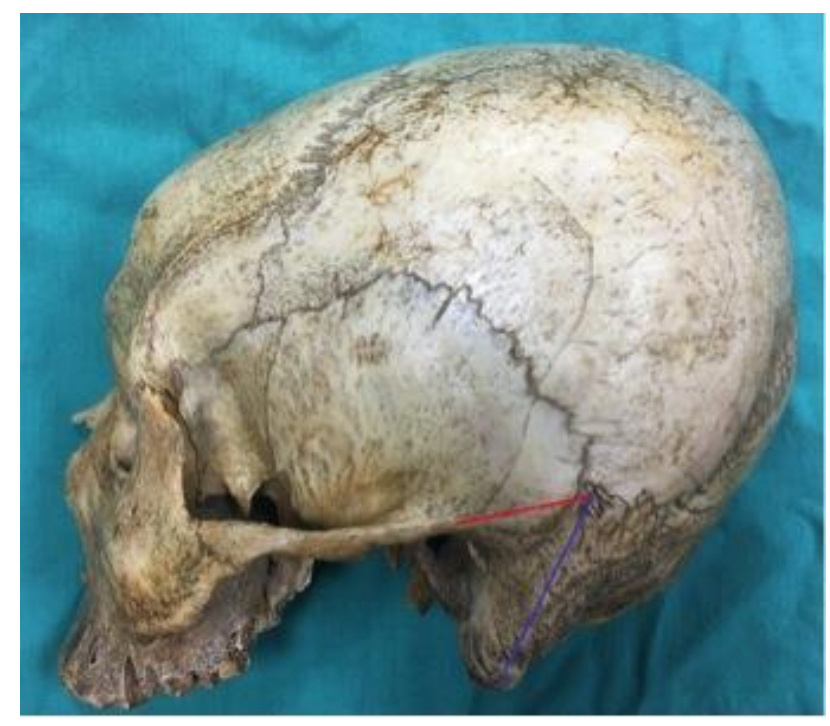

Distance between asterion and posterior end of zygomatic arch

Distance between asterion and mastoid process

mind to prevent misdiagnosis. In our samples all asterions had Type 2 morphology. In their study Deepak et al reported that Type 2 was more common than Type 1 (20). Ahad et al also studied the presence of Wormian bones in asterion. They revealed Type 2 incidence $68 \%$ (21). Study of Ahad et al, study of Deepak et al and the present study are identical in terms of asterion type.

Asterion is a reliable landmark for proper craniotomy. Location of asterion is of critical importance in posterior cranial fossa and posterolateral cranial base surgery (17). Burr hole formation and following craniotomy is the first step of surgical approach which prevents complications and long surgery time $(1,4,5,17)$. Underlying asterion is the junction of transverse sinus and sigmoid sinus and overlying asterion is scalp $(2,17)$. Surgeons use palpable bony landmarks for proper orientation of asterion location. There are studies in the literature determining these bony features $(1,17,18)$. Leon et al determined safety zone by four points and a plane: root of zygomatic arch, suprameatal spine, apex of mastoid process, external occipital protuberance and Frankfurt horizontal plane. Lambda which was included in our study was not mentioned in the study of Leon et al. Suprameatal spine and Frankfurt horizontal plane were not included in the present study. Leon et al found the distance between external occipital protuberance and asterion $61.51 \pm 7.44$, distance between posterior end of external occipital protuberance and asterion 54.74 \pm 4.46, distance between asterion and apex of mastoid process was 51.53 \pm 4.97. Right and left sided distances were not mentioned in details. In the present study we

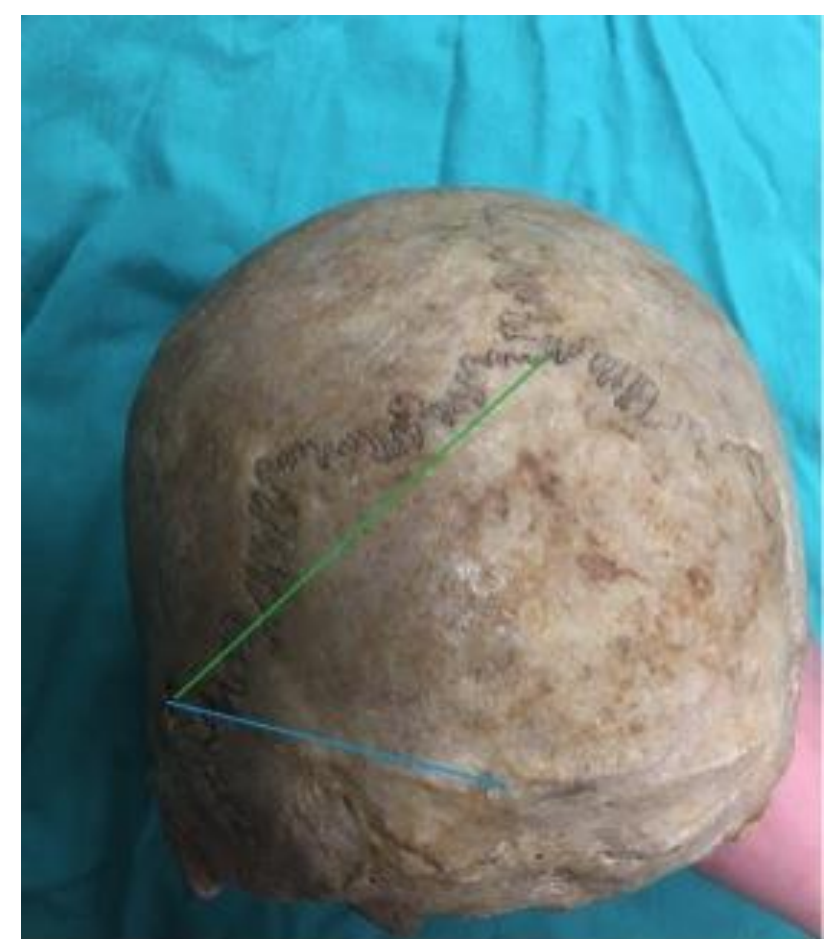

Distance between asterion and lambda Distance between asterion and external occipital protuberance

measured the distances either on right and left sides (18). This point is an additional value of our study.

Underlying asterion is the junction of transverse sinus and sigmoid sinus. Surface projection of sinuses should be known to prevent laceration. Çırpan et al suggested that surgical approach through the zone 10 $\mathrm{mm}$ superior and $10 \mathrm{~mm}$ inferior to asterion carries high risk to damage sigmoid sinus and transverse sinus (22). Relation of junction of sigmoid and transverse sinuses were previously studied in study of Leon et al. They found that junction of transverse and sigmoid sinuses was located at the asterion in $82.4 \%$ of the cases, above the asterion in $12.5 \%$ of the cases and below it in $5.1 \%$ of the cases (18). Mwachaka et al concluded that majority of the cases had junction at asterion in their data. They presented only one case having transverse-sigmoid sinus junction located below asterion (17). Our data was in consistent with the literature in terms of relation between asterion and junction of sinuses.

Asterion is the essential point to indicate safety zone for surgical approach and to determine sex and age. It is of great interest of anatomists, anthropologists, forensic experts, radiologists and neurosurgeons. Asterion is a reliable landmark which indicates surface projection of sigmoid and transverse sinuses.Its location should be known to prevent laceration of dural sinuses during surgery. Present study carried on dry skulls will give idea to scientists for the future studies. 


\section{References}

1. Ucerler H, Govsa F. Asterion as a surgical landmark for lateral cranial base approaches. Journal of Cranio-Maxillofacial Surgery 2006; 34: 415-420.

2. Vrionis FD, Robertson JH, Heilman CB, Rustamzedah E. Asterion meningiomas. Skull Base Surg 1998; 8: 153-161.

3. Satpute C, Wahane A. To study the anatomical variation of asterion in human dry skulls in vidarbha region. Int J Sci Res 2013; 2319-7064.

4. Uz A, Ugur HC, Tekdemir I. Is the asterion a reliable landmark for the lateral approach to posterior fossa? Journal of Clinical Neuroscience 2001; 8: 146-147.

5. Lang J and Samii A. Retrosigmoidal Approach to the Posterior Cranial Fossa. An Anatomical Study Acta Neurochir (Wien) 1991; 111: 147-153.

6. Natsis $K$, Piagkou $M$, Lazaridis $N$, et al. Incidence, number and topography of Wormian bones in Greek adult dry skulls. Folia Morphol (Warsz) 2019; 78: 359-370.

7. Sudha R, Sridevi C, Ezhilarasi M. Anatomical Variations in the Formation of Pterion and Asterion in South Indian Population. Int J Cur Res Rev, May 2013/ Vol 05 (09)

8. Madadin M, Menezes RG, Al Dhafeeri O, et al. Evaluation of the mastoid triangle for determining sexual dimorphism: A Saudi population based study. Forensic Sci Int 2015; 254: 244.e1-4.

9. Orish CN, Didia BC, Fawehinmi HB. Sex Determination Using Inion-OpistocraniumAsterion (IOA) Triangle in Nigerians' Skulls. Anat Res Int 2014; 2014: 747239.

10. Jaja BNR, Ajua CO, Didia BC. Mastoid Triangle for Sex Determination in Adult Nigerian Population: A Validation Study. J Forensic Sci, November 2013; 58: No. 6

11. Cirpan S, Aksu F, Mas N, Magden AO. Coexistence of Wormian Bones With Metopism, and Vice Versa, in Adult Skulls. J Craniofac Surg. 2016; 27: 493-495

12. Çalışkan S, Oğuz KK, Tunalı S, Aldur MM, Erçakmak B, Sargon MF. Morphology of cranial sutures and radiologic evaluation of the variations of intersutural bones. Folia Morphol 2018; 77: 730-735.

13. Rao TR, Rao RS. Anatomical Variation of Asterion in Human Dry Skull- A Case Report. Case Studies Journal ISSN (2305-509X)-Volume 5, Issue 5-May. 2016.

14. Havaldar PP, Shruthi BN, Saheb SH, Henjarappa K S. Morphological Study on Types of Asterion. Int J Intg Med Sci 2015; 2: 167-169.

15. Singh R. Incidence of Sutural Bones at Asterion in Adults Indians Skull. Int J. MorphoL 2012; 30: 1182-1186.

16. Basnet LM, Shrestha S, Sapkota S. Prevalence of wormian bones in dried adult human skulls: an osteomorphometric study in Nepal. Anatomical Science International 2019; 94: 101-109.

17. Deepak S, Dakshayani KR. Morphometric features of asterion in adult human skulls. Int J Res Med Sci 2015; 3: 1325-1328.

18. Ahad M, Thenmozhi MS. Study on asterion and presence of sutural bones in South Indian dry skull. J. Pharm. Sci. \& Res 2015; 7: 390-392.

19. Mwachaka PM, Hassanalı J, Odula PO. Anatomic Position of the Asterion in Kenyans for Posterolateral Surgical Approaches to Cranial Cavity. Clin Anat 2010; 23: 30-33.

20. Galindo-de León S, Hernández-Rodríguez AN, Morales-Ávalos R, Theriot-Girón Mdel C, Elizondo-Omaña RE, Guzmán-López S. Morphometric characteristics of the asterion and the posterolateral surface of the skull: relationship with dural venous sinuses and neurosurgical importance. Cir Cir 2013; 81: 251-255.

21. Çırpan S, Yonguç GN, Sayhan S, Eyüboğlu C, Güvençer M. Morphometric evaluation of localisation of asterion for intracranial approaches posterolaterally. Ege Journal of Medicine 2019; 58: 108-114. 